\title{
Chaperones: friend or foe, and to whom?
}

$\mathrm{M}$ edical regulators have long recommended the use of "chaperones" to make patients feel more comfortable during sensitive examinations.

But standards of practice vary considerably across Canada and guidelines about when to use a chaperone and whether patient consent is required are somewhat hazy and often left to physician interpretation.

What's more, there's growing concern among patient advocates about who chaperone policies actually serve, particularly as there's been increasing call in recent years by medico-legal societies for more routine use of such attendants to protect physicians from allegations of impropriety.

Undergoing an intimate examination shouldn't feel "like being searched at the airport," says Sholom Glouberman, president of the Patients' Association of Canada. "If all of this is based on the growing trend towards less trust and less connection between patients and practitioners, then it makes the relationship even harder and makes the situation more unpleasant and more intrusive."

Chaperone use is not mandated by any regulatory body in Canada, except in cases where it is a condition of an individual physician license. Medical regulatory authorities, however, do offer some advice.

For example, the College of Physicians and Surgeons of Ontario leaves it for physicians to decide whether to offer patients the option of having a third party present (www.cpso.on.ca/uploaded Files/downloads/cpsodocuments/policies /policies/sexual_abuse_boundaries.pdf). The College of Physicians and Surgeons of Prince Edward Island places an onus on patients to ask for chaperones (www.cpspei.ca/publications ?action=view_entries\&id=1), while the College of Physicians and Surgeons of New Brunswick says either patients or physicians can insist on a witness in situations that make them feel uncomfortable (www.cpsnb.org/english/Guidelines /guidelines-1.html).

The College of Physicians and Surgeons of British Columbia provides perhaps the most comprehensive guide-

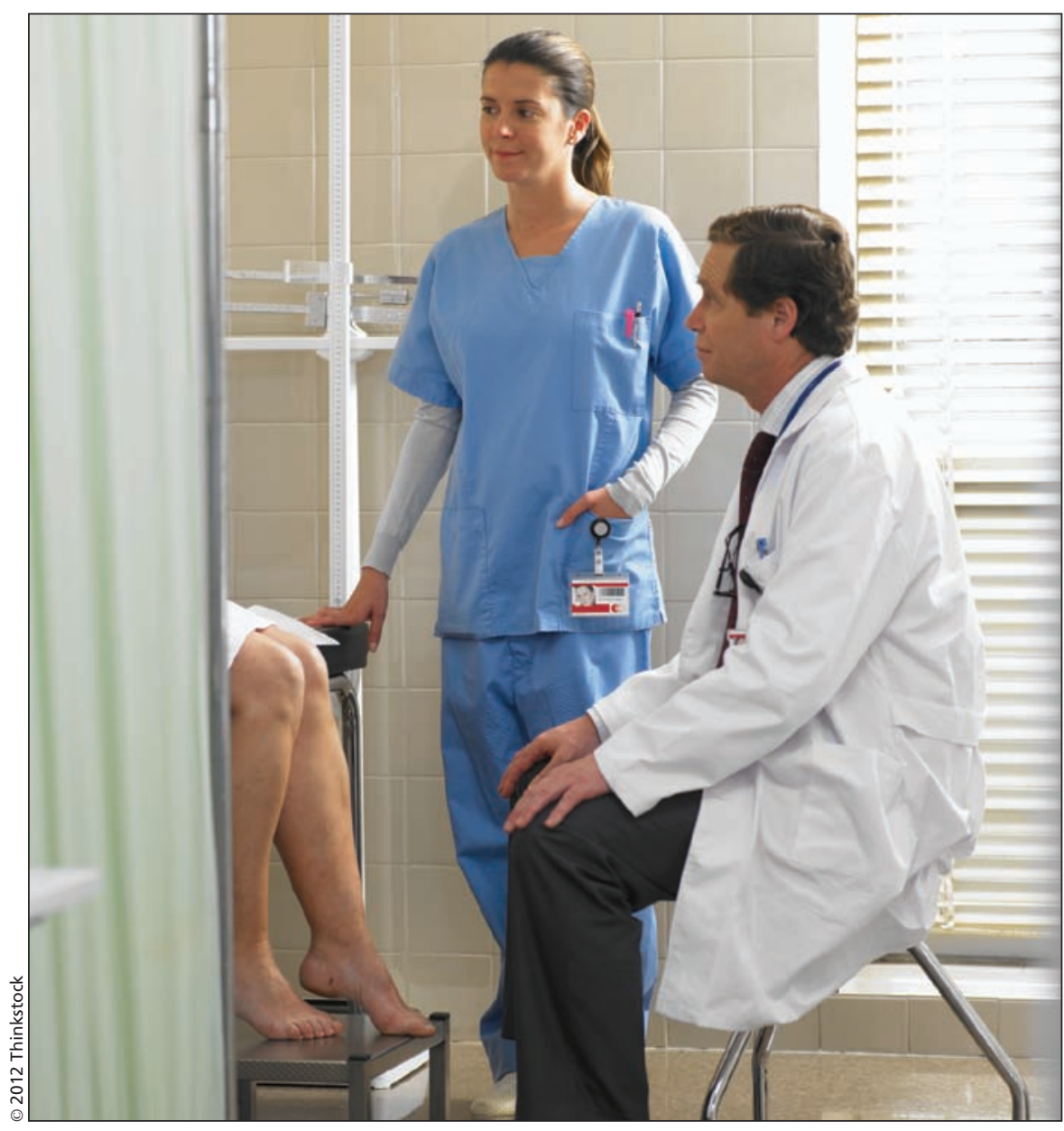

The use of chaperones during physical examinations is intended to put patients at ease, while protecting physicians from liability.

lines. A chaperone's presence may be necessary "if the patient is mentally handicapped, subject to delusions or paranoia, exhibits seductive behaviour, exhibits anxiety about a proposed examination ... is a survivor of abuse, or has other emotional or cognitive challenges which may lead to misperception or misinterpretation" (www.cpsbc.ca/files /u6/Sensitive-Examinations.pdf).

But for the most part, physicians are left to rely on their own intuition.

"What we say is weigh it all out," says Dr. Janet Wright, assistant registrar for the College of Physicians and Surgeons of Alberta. "If you're with a brand new patient you don't know and your 'spidey senses' go off ... it's a good idea to have someone else in the room until a long-term relationship is established."

Others contend this intuitive approach may be exposing physicians to increased risk of allegations from patients who, for whatever reason, don't set off those internal alarm bells.

Many physicians forego the use of a chaperone depending on the procedure or the gender of a patient, says Dr. Ross Upshur, Canada Research Chair in Primary Care and professor of family and community medicine at the University of Toronto in Ontario. Chaperones are more commonly used with female patients, while male doctors are about 40 times more likely to use a chaperone, he explains. "Female physicians are less likely to have a chaperone present while doing intimate examinations on female patients. Similarly, male physicians are less likely to have chaperones present when they're doing intimate examinations on men."

Therein may lie a "false sense of security," considering both male and 
female patients have leveled accusations against physicians, in some cases, regardless of the level of intimacy of the procedure performed, Upshur says.

Dr. Ed Schollenberg, registrar for the College of Physicians and Surgeons of New Brunswick, concurs, citing a recent case in which a woman complained about a female physician because she felt unnecessarily exposed during an intimate exam. "Being the same gender doesn't offer as much protection as one might think [because] it's not always about sex," he says.

"We've tended to see the benefit of the attendant as a function of the kind of examination that's being done," he adds. Yet physicians have been accused of impropriety "during the course of what otherwise would not be an exam where you would think an attendant would be necessary" such as "examining a musculoskeletal injury."

Because of that, medico-legal experts and the Canadian Medical Protective Association have urged more routine use of chaperones and detailed documentation of sensitive examinations and discussions of intimate problems (Can Fam Physician 2001;47:1732-1734).

But some patient advocates worry that the emphasis on protecting doctors from liability undermines the goal of putting patients at ease. "I don't blame doctors for this but I think they're being put into a defensive mode that's really not appropriate," Glouberman says. "By placing more and more security requirements ... it's difficult to establish the kinds of relationships that are necessary [to develop] mutual trust and a chance for that to flourish."

There's also a dearth of detailed guidance on how to balance the use of chaperones with patient privacy, particularly in cases where a physician wants a chaperone present but a patient does not. Such cases fall into a "little gray area" of current guidelines, Upshur says.

As a result, the College of Physicians and Surgeons of Nova Scotia urges doctors to obtain "explicit consent" from patients if third parties are to be present during an examination (www.cpsns .ns.ca/greatphysicians.aspx).

Doctors in some jurisdictions skirt the issue by simply introducing chaperones as "assistants," says Dr. Joel Sher- man, a cardiologist and advocate for patient privacy based in Waterbury, Connecticut. "Most male doctors doing pelvic exams feel they have no choice."

But misleading patients in such a fashion is an "affront to patient privacy," he says.

Still, many Canadian physicians bring chaperones into the examination room without comment or explanation, Schollenberg says.

Patients may be made uncomfortable by the direct offer of a chaperone because it hints at an expectation of impropriety, he explains. "I'm not sure it requires explicit consent because I think there's some expectation on the part of the patient that there's going to be other people around."

But Dr. Samantha Kelleher, deputy registrar for the College of Physicians and Surgeons of British Columbia, says physicians who opt to have a chaperone in the examination room also have a "responsibility to explain" their rationale and offer referrals to patients who fear their privacy may be compromised.

"If physicians have a straightforward approach to their use of chaperones then I think it becomes much easier," Kelleher says. Ensuring that patients are informed in advance, through such means as signs in waiting rooms, is preferable to last-minute notice that a physician wants a chaperone present, she adds.

Dr. Victoria Davis, a member of the Society of Obstetricians and Gynaecologists of Canada's Social and Sexual Issues Committee, concurs. But such a policy should be applied to all patients equally, as the greatest damage to the doctor-patient relationship occurs when patients feel they are being singled out as untrustworthy, she adds. "That's a big drawback [of using chaperones on a case-by-case basis]. At that point you're probably breaking that relationship." - Lauren Vogel, CMAJ

CMAJ 2012. DOI:10.1503/cmaj.109-4127

Editor's note: First of a two-part series.

Part 2: Who should be privy to your privates? (www.cmaj.ca/lookup/doi /10.1503/cmaj.109-4129). 